\title{
Agricultural Extension: Challenges of Extension service for rural poor and youth in Amhara Region, North Western Ethiopia. The Case of North Gondar Zone
}

\author{
Mrs.Tigist Petros ${ }^{1}$, Dr.Kavitha Nachimuthu ${ }^{2}$, Mr. Haimanot Atinikut ${ }^{3}$, Mr. Mohammed ${ }^{4}$
}

Director - Gender and HIV /AIDS, University of Gondar, Ethiopia

Associate Professor, Department of Rural Development and Agricultural Extension, College of Agriculture and Rural Transformation, University of Gondar, Ethiopia.

Lecturer, Department of Rural Development and Agricultural Extension, College of Agriculture and Rural

Transformation, University of Gondar, Ethiopia.

Gedefaw, Lecturer, Department of Natural resources Management, College of Agriculture and Rural

Transformation, University of Gondar, Ethiopia.

\begin{abstract}
:
Ethiopia is one of the countries on the African continent with highest agricultural potential. Its natural resources base is the foundation of any economic development, food security and other basic necessities of its people. Predominantly smallholder agriculture is the dominant sector of the national economy. Smallholder agriculture is the dominant sector of the national economy. To boost the production and productivity of the agriculture sector; the extension systems is expected to play paramount role. However, the agricultural system is still characterized by low level of Agricultural service delivery practice that couldn't move the existing traditional agriculture in to modern. The objective of the study is toexamine constraints in addressing women farmers and rural youth and to assess constraints of extension system in promoting agricultural technologies to farmers in the study area. Primary and Secondary data was collected for the study purpose. In addition to respondents' interview, focus group discussion, key informants interview and case studies were used for qualitative data analysis. Descriptive statistics of mean, standard devotions and percent was applied. For statistical tests, chi-square, T-test, Pearson and spearman's correlation coefficient were employed. As a conclusion, the challenges of existing public agricultural extension service provision institutional, technological and technical and in terms of addressing cross-cutting issues such as environment and gender as theses have wider contexts to look into existing endogenous and exogenous constraints.
\end{abstract}

Key words: Agricultural Development, Stakeholders,Rural youth, Technical and Natural resources

\section{Introduction}

In North Gondar zone, an integration of relevant stakeholders for combined effort in agricultural development activities need further strengthening. Changing this weak agricultural information and knowledge system among actors to holistic approach and strong integration of stakeholders is a very essential action to be done. Then, in order to apply this holistic approach, identification of the main stakeholders and their roles and responsibilities, assessing their linkage and analyzing the factors affecting stockholders integration in implementing Agricultural Extension in the study areas need to be studied, but systematical and empirical study was not attempted so far. Therefore, the proposed study addresses this research gap and tries to make empirical inferences to provide valuable research outputs, that could be used by farmers, government and NGO's who are participating in agricultural development process as well as policy makers in planning appropriate mechanisms that would improve actors integrations, knowledge and information sharing in order to achieve agricultural development. 
To realize agricultural development, it is agricultural extension agents, particularly in developing countries, which are the main actors in delivering extension services to farmers. In listing the essential components of extension service puts extension agents as critically necessary stakeholders (Roling, 1988). This is especially true in developing countries where the majority of the farm households are unable to read and write and have low opportunities to get support from other sources. In the developed countries farmers can, in most cases, directly get information and advice from various sources and subject matter specialists through the use of information and communication technologies (ICT) such as mobile phone, e-mail, internet, fax and the like. Ethiopia, like many developing countries, is not at that stage; so the role of extension agents in the delivery of agricultural extension service will remain vital.

\section{Objective of the Study}

- To examine constraints in addressing women farmers and rural youth

- To offer suitable suggestion to implement the agricultural extension practices

\section{Research Methodology}

\section{Sampling and Data Collection Methods}

- The data were dependent on primary and secondary sources. The farmers, who are the beneficiaries and main actors of agricultural extension; development agents (the extension service provider), different institutions, which are involved as direct and indirect actors of agricultural extension service delivery and technical experts at different were the main actors participants of the study. Multi-stage sampling technique was employed to catch representative areas and sample respondents for the study. First, North Gondar Zone was purposively selected taking its representation of different agro-ecology and relatively larger coverage in the regions. Among 23 districts (Woredas), three districts namely, Wogera form highland (Dega), Demibia from midland (Woina Dega) and Metma from lowland (Kolla) areas were selected using purposive sampling techniques. From each district, 3-4 kebeles were selected using different representations in term of access to agricultural extension services. The distance from district center and availability of road and facilities were also considered as criteria of selection for kebeles. Then household respondents were selected from each Kebele using simple random sampling technique and 120 household respondents were taken from the three districts. Data were collected using different techniques and tools. Household survey using structured and semi-structured questionnaire; focus group discussion with farmers, agricultural extension stakeholders and extension experts and observation of farming systems, settlement pattern, available infrastructure including communication technologies and farmers training centers were important data collection techniques of the study.

\section{Methods of Data Analysis}

- Data gathered from different sources, were organized and analyzed using quantitative and qualitative techniques. The quantitative data were analyzed mainly using different descriptive statistics. To see relationship between different categorical variables, Chi-square test was also used. Correlation and simple linear regression analysis were also used to see the relations between and association among different socio-economic variables and access to agricultural extension service. The data obtained using focus group discussion, key informant interview and case studies were analyzed using qualitative techniques.

\section{Results and Discussions:}

- Rural development and attaining household security in development countries are responses of public agricultural extension (Rivera and Qamar, 2003). However, in many developing countries including Ethiopia, the strong association between the rural development and reduction of poverty has not attracted the attention of policy makers, planners and implementer of the agricultural extension system. Anticipated outcomes of agricultural extension system deliver have not met and the improvements in the lives of agrarian society have yet been in its immovable position and remained unanswered question of the rural development. This is mainly due to the fact that public agricultural extension service, which is the only way in Ethiopia (Spielmanet al, 2011), has been challenged by different factors including institutional, technical, technological and geographical in many cases.

- Public agricultural extension in the country at large and the study areas particularly, has been challenged by different exogenous and indigenous factors. These factors are in one or another ways associated with 
the system in which the process of the agricultural knowledge and technology transfer is undertaken. Agricultural knowledge and technology transfer of the system in the country commands unidirectional, top-down approach, in which the role of the indigenous knowledge and participatory planning based specific felt needs of the poor, are seldom taken into account. The technical aspects of extension experts, who are major planners, facilitators, promoters, demonstrators and managers of agricultural knowledge and technology transfer is in many cases is observed to be the challenging issues for agricultural extension in Amhara Region. The problems with expert technical aspects are emanated from lack of adequate and /or sufficient theoretical and technical knowledge and mismatch between theory and practices. General recommendation and attempts to promote any technologies considering as they are fitting to all, regardless of the need of famers, compatibility of the areas, faming systems, soil types and agricultural commodities is also observed to be the bottleneck of the public agricultural extension service. The following sections presents the specific challenges that public agricultural services facing in the region generally, and North Gondar Zone specifically based on the data generated from household survey, group discussions and observations.

\section{Institutional Aspects of the Agricultural Extension}

- There are different options through which agricultural extension is facilitated and managed (Rivera and Kamar, 2003). In terms of service delivery and funding, the only responsible body in Ethiopia is government by channeling through ministry of agriculture. Structural decentralization of agricultural extension from regional level to lowest administrative structure known as Kebele, in most cases with required personnel in the fields of crop production, animal production and natural resource management and in some potential areas with expert in irrigation is found to be important step-forward observed in institutional organizations. Although, such structural arrangements exist, the knowledge and agricultural technologies transfer have been attempted through top-down command and recommendations, where as demand driven and participatory planning and implementation is neglected, technologies are misused and not in line with diverse production systems.

- Top-down recommendation of agricultural technologies and knowledge transfer systems has resulted in poor feedback-as extension agents and farmers don not have strong and regular connection with the sources of technologies and clients. The data obtained from household survey show that $73.3 \%$ of farm households are willing to provide feedback about the agricultural technologies they are using, but constrained by the distance of the service provision centers and weak interaction with extension experts.

\section{Technological Aspects}

- Demanded, appropriate, affordable and technical feasible technologies have significant role in increasing agricultural production and productivity and lead to improvement of the livelihoods of vast majority. Agricultural technologies requirements are responses of to the demand of the farmers and felt problems in crop and livestock production. It is apparently important to look the crops and livestock production constraints before the evaluating the existing technologies.

- Crop production, which is the main sources of income for about $68.3 \%$ of rural households in the study area is also the primarily the source of food for farm households. As far as the production is concerned there is slight incremental trend in gross product. However, evidences from different sources including the qualitative data of this study indicated that much of the increase in agricultural output in the last decade was achieved by expanding land under crop cultivation, which clearly show the contribution of the agricultural technologies not significant. The limited supply of inputs such as improved seed, fertilizer and high price of inputs particularly highly inflated prices of fertilizer is the major pressing issues of the highland farm households. The problems of the weed, labor shortage especially during the peak times of weeding and harvesting in the lowlands of the study areas, pest and insects infestation, declining trend of the land and soil fertility with its impact on productivity are also observed to be the major constraining factors of the crops production. 


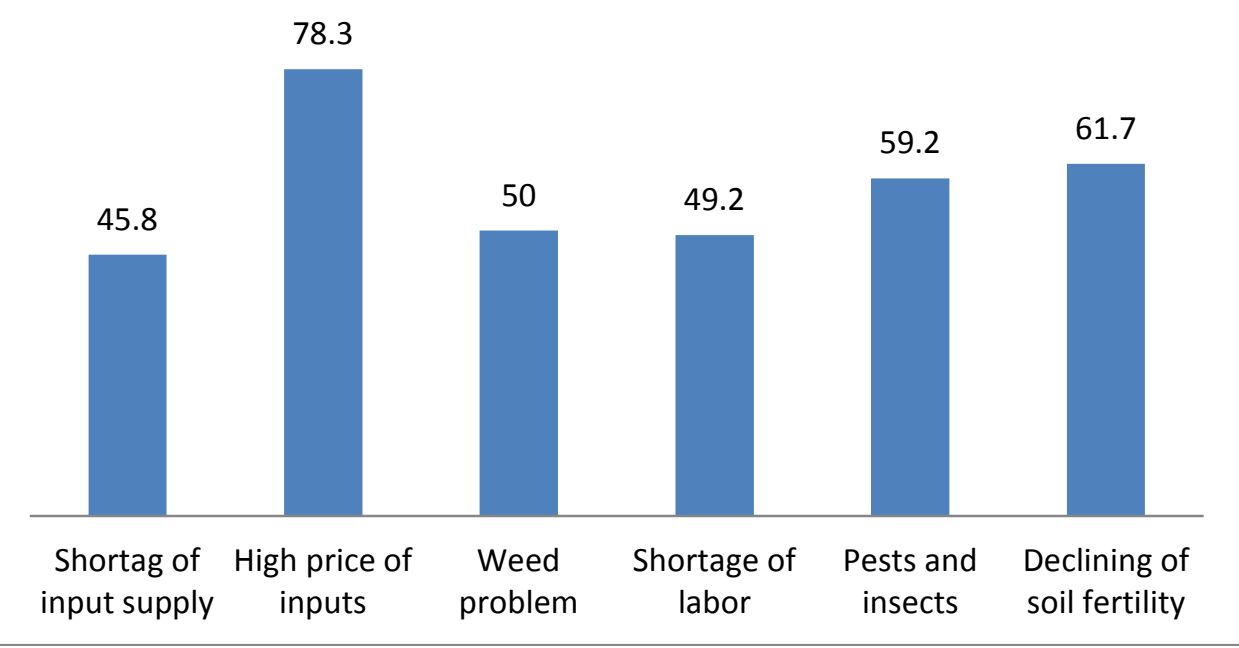

Fig. 1

Source: Household Survey Data, 2016

- Farm plots of smallholders have been dependent of the organic fertilizer for optimum yield and it is becoming an increasing challenge of agricultural extension service provision. The problem is exacerbated as the demand to increase production is increasing where as the cost of fertilizer is also increasing. The soil fertility is also highly associated with inorganic fertilizers utilization and fragmentation plots into smaller and smaller pieces over time.

- Livestock production, which is the integral part of agricultural production plays significant role in the livelihoods of farm households. In the areas where there is no access to financial institutes, livestock production or accumulation serves as the means of the saving. From randomly taken households in the study areas, $8.3 \%$ respondent households reported that their income is exclusively dependent of livestock and their products. The data obtained from household survey of the study population revealed that average livestock holding per household excluding poultry is found to be 5.23 TLU (Tropical Livestock Unite) per household with huge variation between lowlands and highlands of the study areas. The lowland areas including Metema, have relatively larger livestock population per household due to agro-ecological advantages. Like crop production, the livestock component of the agricultural production in the study areas, face different challenges due many factors.

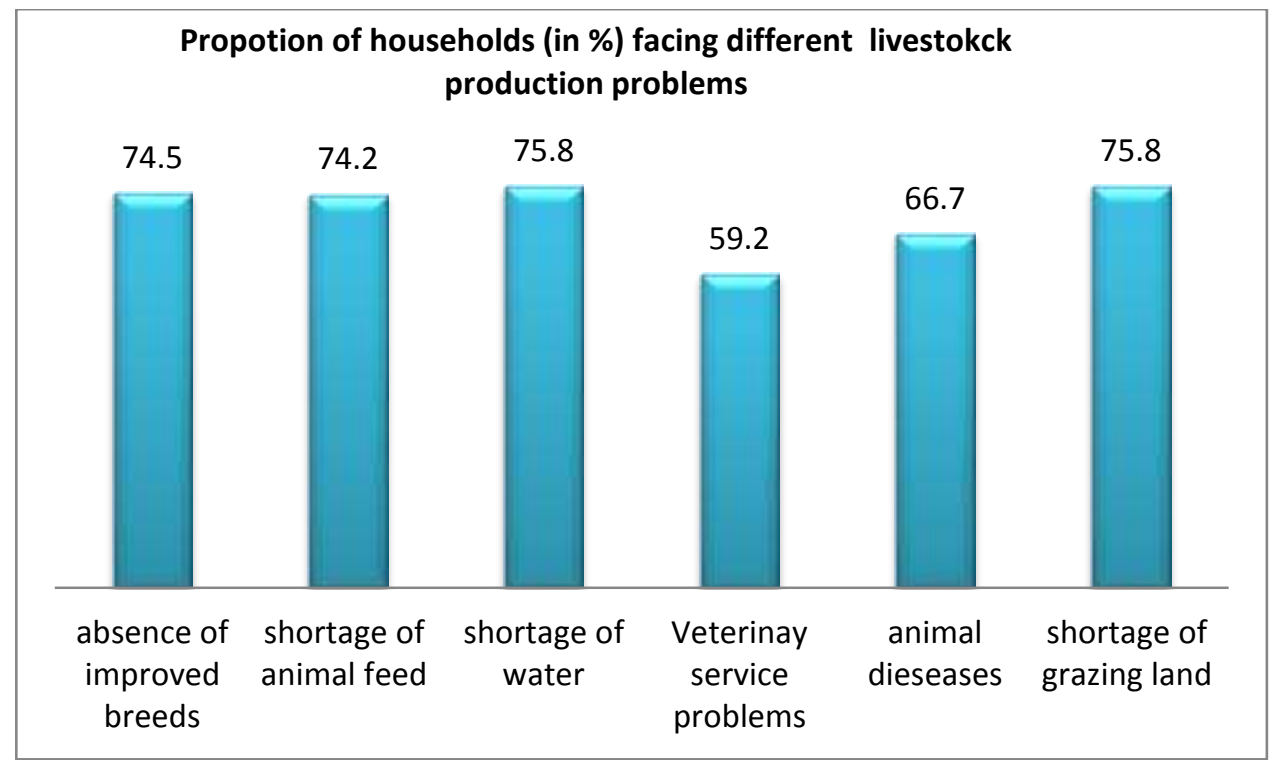

Fig. 2

Source: Household Survey Data, 2016

- Lack of improved livestock breed especially in rural areas, inaccessibility of the veterinary services and demonstration sites, scarcity of animal feed, shortage of grazing land, shortage of water and 
animal disease are found to be major problems of the livestock production North Gondar Zone of Amhara Region.

- The major components of agricultural production have been constrained by different challenges, which require innovative technological responses to tackle the root causes and bring the system to the desired and gainful practices. Moreover, climate and environmental change problems are threatening production system and livelihoods of the rural households than ever and expected to continue along with declining trends of natural resources including forest, waters and degradation of soil. In this regard, it is apparently important to question existing agricultural technologies, whether they are demanded or commanded, the short comings and their ability to address the pressing problems of the farm households.

\section{Agricultural Technologies in Place}

- To increase agricultural production and productivity through extension advisory and dissemination of technologies to farmers is more of theoretical and political than practice in the context of the Amhara Region. In connection with this, Rural Development Agricultural Extension Series report of World Bank in 2010, revealed that public agricultural extension service in Ethiopian and other developing countries is characterized by the tendency of politicians providing extension services to clients in exchange of political gains. Since the inception of the agricultural extension in the country, there are long lasting attempts in this regards in all parts of the country. The same is true in the study area with limited access to agricultural information and technologies. In principle and structurally, almost in all parts of the study area, there are concerns that extension services is focusing on pressing issues of agriculture including crop production, animal production, natural resources management and recently irrigation in some potential areas.

- Crop production enhancement technologies are dominantly focused on fertilizer, improved crop variety and seeds, row planting, pesticide and herbicide application with limited access and geographical disparities. The study has revealed that despite the long lasting efforts in the agricultural extension, yet significant proportion of farm households never advised or get any technical support for different agricultural technologies for crop production by concerned extension service providers.

- The available data from household survey show that agricultural extension advisory service for crop production component, has given less attention to pest management and storage techniques, which are the major causes of pre and post-harvest losses respectively. Considering technological practices as they fit to all areas has been also observed challenges of crop production as political leaders attempt to convince farmers taking the good report of other areas without any adaptation trail and testing to the context.

Proportion of households, who got extension advisory service in \%

got advised never advised
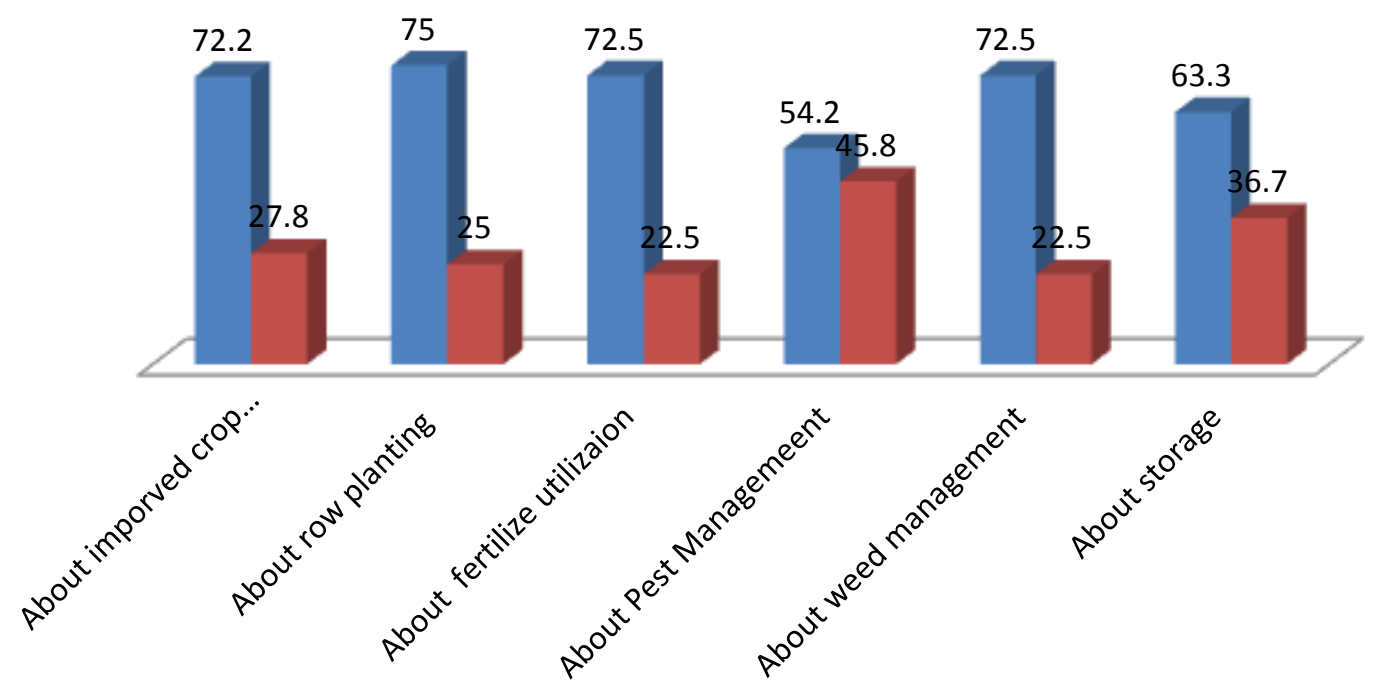
Fig. 3

Source: Household Survey Data, 2016

- Relative to crop production, livestock production and management has attracted less attention in the agricultural extension services in North Gondar Zone, where the demand for improved breads, animal feeds, veterinary services and livestock product processing and marketing is high. Information and access to improved breeds is concerned, $66.7 \%, 65.8 \%$ and $35 \%$ of farm households do not have neither access to information nor for improved breed of milk caw, sheep and poultry respectively. Famers from highland and midland areas relatively have better information about improved poultry and cattle breads. In this regard, the pre-urban and urban areas have good practices for hybrid cattle (in most cases with Holstein Frisians breeds) for milk production compared to rural farm household. As the case in post-harvest handling, the agricultural extension services and technologies in promoting the livestock products such as milk processing and hide and skin is by far blew the expectation where the need and contribution of such product gross domestic production (GDP) is significant. Thought they have their own technical and managerial problems, dairy cooperative in urban areas have relatively better experience in processing and marketing in Cities such as Gondar, but as important stakeholders for agricultural extension, they have limited practice in disseminating the diary processing technologies to the nearby rural areas. The data obtained from household survey of randomly taken respondents tell us $77.5 \%$ of farm households do have any information and practice about handling and management of skin and hides, whereas the rest $22.5 \%$ of respondents have information about good handling and management, but don't have any practices. The effect of these is hid and skins supplied by the vast majority of the rural community have poor quality and farmer loss expected benefits from byproduct livestock.

- Public agricultural extension service is responsible to promote natural resources sensitive agriculture both in crop and livestock production. The ever increasing climate change and its impact on global warming has become pressing issue of the contemporary world. Moreover, according to the United Nations Framework Convention for Climate Change 2007, the effect of the climate change on developing counties including Ethiopia is comparatively higher. The study questions in what ways public agricultural extension services in the areas is supporting environmental friendly production system. Based on data obtained from survey, $75.8 \%$ of households do have information and practice about soil and water conservation. However, the natural resources conservation activities have been undertaken in mass mobilization of community based on top-down plan of the government in the name of green economy. The natural resources conservation activities in the form of campaign is the clear indication that agricultural activities with full participation of the community has got less attention and it not institutionalized as there is decentralized structural arrangements of agricultural extension under each lowest administrative levels. On the other hand, there is geographical variation in natural resource conservation campaigns and it is mainly undertaken in highlands and midlands, where the natural resources are degraded due frequent cultivation over a centuries. In the lowland areas, where there is relatively diverse natural forest, the attention given for conservation agriculture and protection of natural resources very less. This can jeopardize the loss of natural resources and expansion of desertification along with devastating impacts of climate change.

- The soil and water conservation activities at farm level are very important extension intervention and there had been different attempts in the study area and other part of countries especially where vertisol dominantly found. Broad Bed Maker (BBM) technology is believed to be helpful to avoid water logging problems. Despite anticipate positive impact of the BBM technology, smallholder farmers did not adopt even in the areas, where the existing situation is demanding it because of different reasons. Incompatibility of the technology to existing farming tools and absence of technical support from extension agents are found to be the reasons behind failure of the specified technology. An interesting finding with regard to BBM technology is there is blind recommendation to the area where there is no need for it through agricultural offices.

- Availability, compatibility to the environment and farming system and affordability of agricultural technologies are the main factors for sustainable application and use by smallholders. As it was witnessed by $45 \%$ of sample respondents, the existing technologies of agriculture did not consider 
environmental issues. In all parts of the study area, using pesticide is found to common practice regardless of the knowledge and practices on application and safety precautions. There is observable impact of pesticides application in beekeeping, which is the ideal climate smart agriculture, as there is loss of grasses and residual effects for the death of bees in lowland areas include Metema.

- Availability and affordability of technologies significantly affects the utilization of agricultural technologies as it is observed in north Gondar of Amhara Region. The high cost of the technologies such as improved seeds, machineries and fertilizers is the challenged for farm households. Applying inorganic fertilizer for most of the highland and midland famers is mandatory as their plots have already developed dependency on it, but the high cost has forced the famers to use below the recommended rates of application. On the other way, there is forced recommendation of organic fertilizer to the areas, where there is no demand for it and there are also farm machineries, which their applications and operation are not known by farmers and even by extension agents.

- The practical observation of all agricultural technologies in different areas revealed that there are huge gaps in demand and supply of technologies. The demanded technologies of agriculture in most cases improved seeds and verities such as Malt Barely as the case in Wogera district are introduced without recommended full pack of production. The high cost, poor quality and limited variety of agricultural technologies are the major bottlenecks to promote the needed technologies to the needy smallholder farmers. The weak agricultural extension system in the study areas and absence of other alternative technologies have resulted in unnecessary or higher cost for smallholder farmers and waste to public institutes due technical and managerial pitfalls.

- In general, there is mismatch between existing crop and livestock production and natural resource problems and available agricultural technologies. The agricultural technologies in place are neither based on the problems smallholder agriculture nor sufficient to the needs of smallholder farmers in North Gondar of Amhara Region. This finding has more to share with the study conducted by (Belay, 2003). As he has vividly noted, different extension approaches in Ethiopia have been planned and implemented without the participation of the very people for whom they have been designed. The finding of the this study consolidate the case as planning and transfer of technologies follows top-down approach and is commanded than demanded by the needy people along with the lost linkage between farmers, extension workers and the sources of technologies.

\section{Technical and Communication Skills of Agricultural Extension Agents}

- Effectiveness, efficiency and quality of agricultural extension service provision are mainly a function of the competency of professionals in terms of the required knowledge, skills and attitudes. Technical and communication skills are paramount important for promotion and dissemination of the technologies. Famers require practical demonstration to adopt agricultural technologies than mere information about certain technology. The data obtained from focus group discussions with farmers indicated that technologies, which have been demonstrated practically, are trusted and practiced. However, the current technology introduction and dissemination strategies are simply based on theoretical judgments than their practical impacts. Thought, there are institutional and resources related problems, low adoption of agricultural technologies in north Gondar is partly due the technical inefficiency of development agents. The data obtained from qualitative source indicated that development agents are not technically equipped to demonstrate the new technologies and also unable to create sustained interaction with clients. Based on the services given to famers, the performance of development agents (extension workers) was evaluated. According to $39.2 \%$ of the sample respondent famers in study areas, development agents are reported to be qualified in term of giving the needed services to their clients and $12.5 \%$ of farm households claimed that they have poorly qualified to provide agricultural extension and advisory and technical services.

- Weak interaction of farmers and service providers could be explained from technological, infrastructural and cultural points of views as they significantly affect communication. Imbalanced extension worker to farmers' ratio (0.0058); absence of continuous technical updates for newly introduced agricultural technologies, frequent turnover of extension workers, which emanated from absences of rewarding incentives and as they seek to promote the local political leaders. In addition to these, geographical barriers have contributed more to inefficiency of extension workers. 


\section{Agricultural Extension in Addressing Women and Rural Youth}

- Public agricultural extension services are for those who have involved in agriculture and to let them better in increasing their capacity through providing applicable information, knowledge and skills. The women and rural youth represent the vast majority of the productive segment in agrarian society including North Gondar Zone of Amhara Region in Ethiopia. It is imperative agricultural or rural extension to address women and youth as important drivers of economy. Owing the fact, the study has attempted to look in what way they have been supported by public agricultural extension services.

- Concerning women, Berhanu et al (2006), has importantly noted that although the role of women in agricultural production and marketing has been well recognized, there is gender bias in the service, whereby the majority of the beneficiaries are male. The study questions whether the exiting public agricultural extension services in the study has given due attention in terms of creating gainful opportunities to women. Compared to men, proportion of women getting agricultural extension services are significantly less in terms of getting advisory services from extension works, but the politics of extension in addressing woman is high. This is partly due to proportion of women extension agents are less than the number of men and men agents tend to contact male headed households than female headed households. Agricultural extension agent contact frequency of female is also less than men as women have multiple roles in addition to their involvement in agricultural production. Moreover, qualitative evidence from focus groups discussions with different representations in all districts of the study areas and field observations revealed that women farmers or women headed households are mostly neglected from agricultural extension duet to the fact that most of extension workers are male and they preferably contact mainly diplomatic male headed farm households. Interestingly, proportionally few female extension agents are better in contacting female headed households and managing all service provision activities than male extension workers in most cases. However, they are few in number and placed in the easily accessible areas and geographically challenging areas are not addressed through female extension workers.

- The fate of future development depends on new generation. Agricultural transformation requires genuine investment on education and empowerment of the most energetic segment of existing productive forces. Apart from formal education, public agricultural education, which is important part of non-formal education, is expected to play significant role. According to different government reports, Ethiopian youth represent about $30 \%$ of the total population and majority of productive forces. Unlike urban youth, who have attracted the transformation plan of the country as major players, rural youth did not receive due consideration and if any intensive agricultural production through small scale irrigation schemes and animal fattening are possible ways among many alternatives.

- According to data generated from both primary and secondary sources, rural youth in North Gondar zone are not benefited from public agricultural extension services even on small scale irrigation based production and animal fattening. They have been trained and capacitated by Technical and Vocation Enterprise Development Office of districts (woredas) on agricultural and non-agricultural enterprises by creating access to credit for initial capital in collaboration with Amhara Saving and Credit Institute (ACSI). In some areas, Nongovernmental Organizations (NGOs) on entrepreneurship skills development rarely provide trainings upon the recommendations of local administrative bodies such as Kebele officials. The challenging issue with these endeavors is the selection process of youth, in which most of times nomination of beneficiaries are based on the political affiliation. Another challenging issue of public agricultural extension in addressing youth is the land tenure issue, in which most of members of people under the category do not have land to cultivate and if any they are dependent on their family plots.

- In general, despite many opportunities to assist youth, public agricultural extension service provision did not pay due attention and the exiting capacity building activities for youth are mainly done by Technical and Vocational Enterprise Development Offices and rarely by NGOs without creating synergy among these stakeholders. 


\section{Conclusion:}

- Persisting challenges of public agricultural extension services provision and its prospects could be seen from different perspectives. Based on imperial evidences of the study from primary and secondary sources, the following are some of conclusion drawn. Apparently, it is important to look the challenges of existing public agricultural extension service provision institutional, technological and technical and in terms of addressing cross-cutting issues such as environment and gender as theses have wider contexts to look into existing endogenous and exogenous constraints.

- Agricultural extension services as institutionalized public activity in North Gondar Zone of Amhara Region has good base to start up for effective and publically demanded technology dissemination and diffusion. Structurally, it has been decentralized to the levels of the lowest attainable public administration stricture known as Kebeles. Identification of public agricultural extension services provision focus areas including the most dominant components of agricultural production (crop and livestock); natural resources conservation and irrigation technologies have been well stipulated. These pressing issues have important role in uplifting the production and productivity and sustainability of agriculture, which can help to o meet the increasing demand its products.

- Structural skeleton of public agricultural extension service provision alone has nothing to do with in the process of assisting smallholder farmers through technical advisory services and practical demonstrations, which lead to positive impact on productivity and livelihoods of needy people (Smallholder farmers), unless they have been fulfilled with required personnel and extension agents having required qualification.

- Major agricultural production components production in North Gondar Zone have suffered from different problems which ranging from input supply to processing and marketing, demanding immediate technical support, technological response and timely information. Existing public agricultural advisory and extension system is not designed and implemented based on felt need of producers and lacks full participation concerned stakeholders. As far as existing agricultural production and available technologies are concerned, there is mismatch between the demand and advisory services and technologies in place.

- Environmental and natural resources issues have threatening agricultural production severely than ever and expected to threaten more with devastating impacts on the lives of the people across glob, especially in developing countries including Ethiopia. However, neither available agricultural technologies nor the long lasting experiences of smallholder farmers have been environmentally friendly and sensitive to climate change. The situation has been exacerbated due to inefficient technical knowledge, commitment, and higher turnover of extension workers, who are believed to be major planners, facilitators and promoter of the public agricultural extension.

- Women and youth are believed to be contributed more for agricultural production and they constitute significantly larger proportion of the population. Despite, their contribution in overall economy of the nation, attention given to them from public agricultural extension services in the study is not in way to support the vast majority and this partly due to cultural, economic, geographical and absence of rewarding incentives.

\section{Recommendations}

The study has revealed many challenging factors of public agricultural extension in North Gondar Zone of Amhara Regions. Based on the major findings of the study, the following are some recommendations forwarded for practical intervention and policy implications.

- It is found that public agricultural extension service is geared towards the crop production, paying less attention for livestock and natural resources management and extension work has been considered as seasonal campaign based interventions by the political leaders. For sustainable agricultural development and impactful agricultural extension, diversifying its services based on existing problems of the farming households is paramount important. Instead of campaign, it should be based on participatory planning and implementation. To this effect, the agricultural extension experts, practitioners, promoters and GOs, and NGOs could play significant roles. The agricultural extension works activities should be led by technical experts aiming to benefit the needy smallholder farmers than for political consumption. 
- There is mismatch between the problems of agricultural production and available but "limited" technologies and services to the farmers. Therefore, it is highly recommended that dissemination and promotion of agricultural technologies should be preceded by proper assessment of the needs and suitability to environment, cultural and economic situation with full participation of clients along with recommended packages.

- Agricultural extension workers, who are major promoter of the knowledge and technology transfer, lack communication and demonstration skills to transfer technologies in most districts of study area. In addition, poor incentive and rewarding mechanisms and the challenges they face due geographical disparities in highlands and harsh climate environment in lowlands resulted in high turnover. To make them important assets of agricultural development, providing technical updates specially skill training, devising incentive and rewarding mechanisms such as resident housing by the local government bodies and stakeholders could fill gaps.

- Empowering rural women and youth, who constitute the majority of productive forces, through agricultural extension and advisory system based on the needs of and using existing opportunities is wise investment for overall transformation of the sector. Therefore, it is highly recommended that agricultural extension program planning and implementation take into account proactive involvement of rural women and youth.

\section{References:}

[1] Asiedu-Darko Emmanuel (2013). Agricultural extension delivery in Ghana: A case study of factors affecting it in Ashanti, Eastern and Northern regions of Ghana. Journal of Agricultural Extension and Rural Development Vol. 5(2), pp. 37 -41, February, 2013

[2] Belay K. 2003. Agricultural Extension in Ethiopia: the case of Participatory Demonstration and Training Extension System. Journal of Social Developmentin Africa, Vol. 18, No. 1, pp 49-83.

[3] Berhanu G., Hoesktra D. \& Azage T. 2006. Commercialization of Ethiopian Agriculture: Extension Service from Input Supplier to Knowledge Broker and Facilitator. IPMS

a. Ethiopia, Working Paper 1.

[4] Elias, A., Nohmi, M., Yasunobu, K. and Ishida A., (2015). Farmers' Satisfaction with Agricultural Extension Service and Its Influencing Factors: A Case Study in North West Ethiopia. J. Agr. Sci. Tech. (2015) Vol. 18: 39-53

[5] Gezahegn Ayele, Mekonnen Bekele and Samia Zekeria .2006. Productivity and Efficiency of Agricultural Extension Package in Ethiopia. The Ethiopian Development Research Institute, Addis Abeba, Ethiopia.

[6] Habtemariam Kassa, 2004. Agricultural Extension with Particular Emphasis on Ethiopia. Ethiopian Economic Policy Research Institute, Addis Ababa, pp 80.

[7] Khalil AHO, Ismai,1 M. Suandi, T. and Silong, AD. (2008). Extension worker as a leader to farmers: Influence of extension leadership competencies and organizational commitment on extension workers ${ }^{\text {ee }}$ performance in Yemen. J. Int. Soc.l Res, 1(4): 358-387.

[8] Rivera W. Mc. and Qamar K. M. 2003. Agricultural Extension, Rural Development and Food Security Challenges. Foods and Agricultural Organization of United Nations.

[9] Spielman D.J., Dawit K., and Dawit A. 2011.Seed, Fertilizer, and Agricultural Extension in Ethiopia. Development Strategy and Governance Division, International Food Policy Research Institute Ethiopia Strategy Support Program II, Working Paper 20.

[10] TewodajMogues,Cohen, M.J.,Birner, R., Mamusha Lemma, Randriamamonjy,J.,FanayeTadesse and Zelekawork Paulos (2009). Agricultural Extension in Ethiopia through a Gender and Governance Lens. Ethiopia Strategy Support Program 2 (ESSP2) Discussion Paper No. ESSP2 007 October 2009. 